\title{
Application of Space Decoration Art of Traditional Residential Courtyards in Guanzhong Area of Shaanxi Province in Square Design
}

\author{
Yiqing Li \\ Xi'an International University \\ Xi'an 710077 China
}

\begin{abstract}
In the traditional residential courtyards in the Guanzhong area of Shaanxi, the application of decorative patterns plays an important role in the formation of the entire style. Guanzhong traditional residential courtyard space decoration art has a very long history. It is attached to Guanzhong traditional architecture and combined with architecture to form a serialized copy of life. This paper first analyzes the basis of the decorative art of traditional residential courtyards in Guanzhong area of Shaanxi Province, and then sorts out the unique natural and humanistic environment of Guanzhong area, which leads to the style characteristics of Guanzhong traditional residential courtyard decoration art. Finally, it analyzes the application of cultural elements in the design of modern squares and proposes to apply the decorative art of traditional residential courtyards in Guanzhong area to the construction of squares. The results show that the traditional decorative art of the residential houses in Guanzhong area of Shaanxi can be effectively applied in the design of the square.
\end{abstract}

Keywords-Art Deco, Square Design, Guanzhong District, Traditional Residential Courtyard

\section{INTRODUCTION}

Traditional architecture is an important testimony to the development of national characteristics and national history [1]. It is a building with regional traditions that people have accumulated over a long period of time. These different kinds of buildings together constitute the characteristics of the region. It is precise because of the different forms of regional architecture that left a different impression in people's minds [2]. Guanzhong residences are constructed in the form of their unique courtyard space. With the evolution of the times, the spatial pattern of residential houses is constantly changing. The form follows the function, but its essence has not changed [3]. The traditional courtyard space has a pleasant scale and distinctive features, and it contains a profound cultural heritage [4].

The residences in Shaanxi consist of three parts: the cave dwellings in the north of Shaanxi, the houses of Guanzhong Courtyard and the houses in southern Shaanxi [5]. Due to geographical restrictions, most of the northern Shaanxi dwellings are caved on the slopes of the slopes. The residences in southern Shaanxi are affected by Sichuan dwellings and Hubei dwellings, while the Guanzhong Courtyard dwellings are the most representative form of dwellings in the Sanqin area. At present, modernization has become the goal pursued by many landscape designers [6]. There have been many works that imitate and copy the modern landscape of the West. As a result, the landscape has experienced great convergence in a certain period of time, and regional characteristics have also been seriously lost [7]. Secondly, there is still a certain degree of understanding of regional culture. A simple understanding of the regional landscape culture is to emphasize the components and traditional styles of the ancient landscape, without thinking about it. This does not fully reflect the characteristics of regional culture. Thirdly, the status quo of China's regional landscape also shows great chaos. Under the impact of the strong culture of the West, it also wants to reflect the regional cultural characteristics. As a result, many works are not inconsistent and not too bad [8].

This paper analyzes and discusses the application of the decorative art of Guanzhong traditional residential courtyards. The decorative art of traditional Chinese residential courtyards in Guanzhong represents the unique cultural connotation of the Guanzhong area, but it is difficult to apply its essence in the construction of the square. Many squares are only a few square landscape pieces or cultural columns in design, and the use of traditional architectural decoration is relatively one-sided. In addition to being constructed with architecture, architectural art can also serve as a heritage.

\section{ANALYSIS OF DECORATIVE ELEMENTS IN GUANZHONG TRADITIONAL RESIDENTIAL COURTYARDS}

\section{A. Guanzhong folk art}

The culture of each region is objectively determined by the natural geography of the region. The natural environment is the cultural soil and foundation of the region. People develop a unique way of living by getting along with nature. When dealing with the natural environment, especially the traditional 
has the advantage of facilitating the discharge of rainwater. There are countless examples.

The long history of the Guanzhong area has made the Guanzhong folk culture highly representative and recognizable in the Han culture circle. There are many kinds of forms, such as clay sculpture, stone carving, wood carving, printing and dyeing, lacquerware, etc. These folk art forms reflect the living conditions and spiritual outlook of people in Guanzhong area, and they are still being passed down and promoted today.

Most of the ancient Chinese buildings are brick and wood structures, so bricks are one of the commonly used materials for architecture. The brick carving is mainly expressed in the building, combined with its easy carving, economical design and simple color. The brick carving shines on the residential buildings in the Guanzhong area. The earliest form of brick carving can be traced back to the Hemudu period in the new era. It can be seen from the unearthed pottery block that the pottery block has been carved with a simple pattern, which can be said to be a simple brick sculpture. After the Western Zhou Dynasty, the Qin and Han Dynasties unearthed, while satisfying their functionality, there are also simple patterns carved on them, which is also an early manifestation of brick carving. Nowadays, the residential buildings in Guanzhong area are mostly built in the Ming and Qing Dynasties. The brick carvings have been developed to be more mature. They can be seen in the entrance walls, walls and horse head walls of buildings, and become an important part of the traditional decoration art of Guanzhong.

\section{B. Guanzhong traditional residential courtyard space decoration components}

The wall is an architectural element that isolates the space. At the same time, there is a lot of space on the façade that can be used as a decoration. It is for this reason that the wall is either plastered or carved, which reflects the importance of the wall as an architectural decoration. Most of the ancient Chinese buildings use pillars as the load-bearing structure. The walls only serve as enclosures and divide the space. Therefore, ancient Chinese architecture can make the walls fall and the houses do not collapse. On the material of the wall, there are mainly earth walls and brick walls. Some earthen walls are built with bamboo and wheat straw to increase their stability. The stability of the masonry wall is better than that of the earth wall, and it is more beautiful than the earth wall.

The cultural connotation of doors and windows is expressed by patterns, reflecting the status of the owner of the building, cultural cultivation, and the symbol of wealth. From the perspective of the history of architectural development, it is the performance of the development of architectural art. The door and window designers skillfully deal with the proportion, curvature, and combination, and represent the spatial structure and combination of doors and windows. The artistry of doors and windows is not only limited to the spatial structure, but also the expression of culture. A large number of patterns can reflect certain historical themes, or operas, etc., and the subject matter is very wide. The proportion of various courtyard forms is shown in Fig. 1.

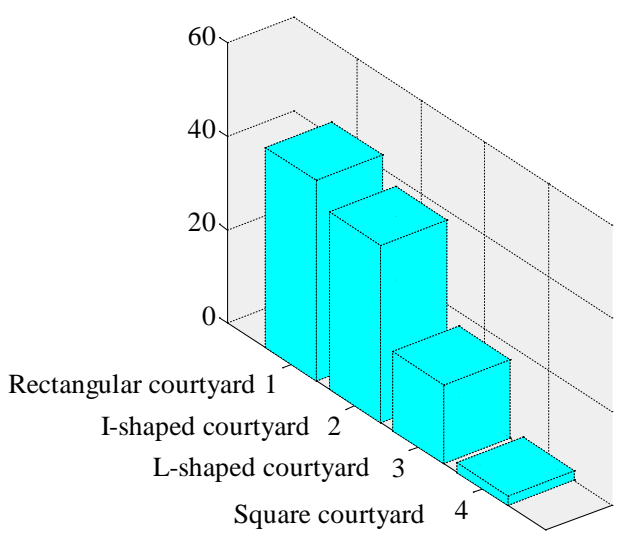

Fig.1. Proportion of various courtyard forms in Guanzhong area

There is a pillar stone in a major feature of Chinese architecture. In ancient China, the pillars in our common traditional buildings were used to withstand the pressure transmitted from the upper part of the building. The walls of the building were not subject to vertical pressure; only the walls were self-weighting and cooperating. Therefore, after the wall part or even the whole is damaged, the whole building will not collapse, which largely guarantees people's safety. The pillar stone is undoubtedly the unity of decoration and realism in terms of volume, theme and form. A small pillar stone contains the superb skills of the craftsmen of that era, and also conveys the master's sentiments and aspirations to the world. The use of skills makes the connotation of the pillar stone richer and deeper.

\section{THE THEORETICAL BASIS FOR THE APPLICATION OF CULTURAL ELEMENTS IN MODERN SQUARE DESIGN}

\section{A. Design elements of the modern square}

The design of modern squares is becoming more and more complicated, not just simply opening up an open space and posing some facilities. First of all, in the location of the square, you should consider the comprehensive, how to live in harmony with the surrounding environment. Secondly, urban square design is a comprehensive design of the urban space environment, which requires multi-disciplinary and multi-work cooperation. The city square reasonably handles the relationship between the urban space environment and the surrounding buildings, providing residents with a comfortable outdoor activity space and achieving the goal of serving "people".

For the design elements of the modern square, the functionality and aesthetics, as well as the cultural nature behind it, are indispensable. Compared with traditional squares, the design of modern squares has changed. Users are no longer only belonging to certain privileged classes. The majority of people are more involved. The desires and methods of people's communication are more urgent and direct. The square is given more features. Therefore, in the modern square division, according to its functionality, it can be divided into sports plaza, entertainment plaza, and memorial plaza and so on. Human needs and square design elements are shown in Fig. 2. 


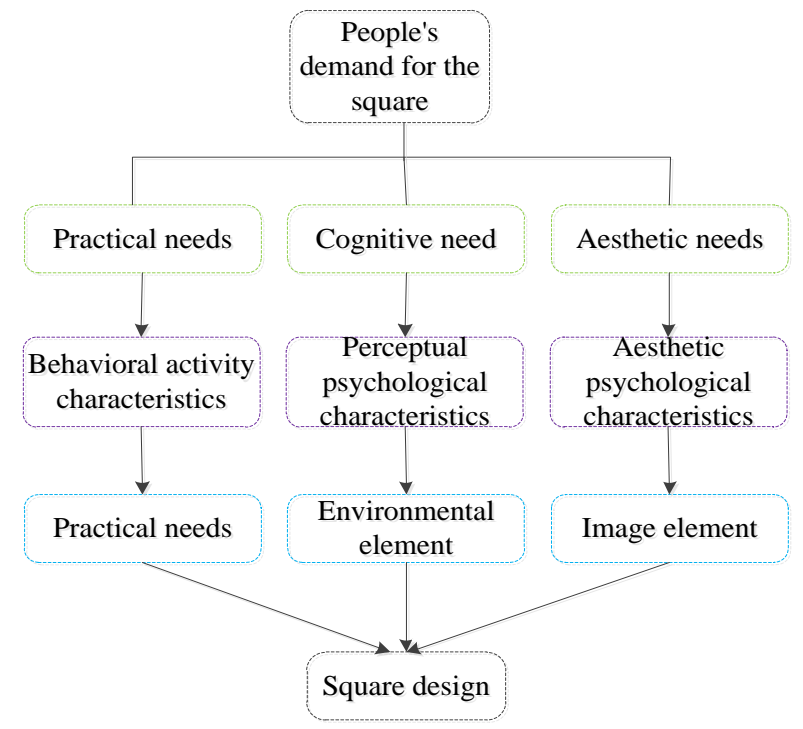

Fig.2. Human needs and square design elements

The aesthetics of the square are constantly changing and developing, and the ways of expressing beauty vary widely, so this also creates the difference in the square. The geometrical shape of the rules once shined in the Roman Forum, and the rhythmic curves once dominated the design of many squares in the Western Renaissance. The easy-to-perform paintings are initiated, which in turn affects the building and then the landscape. There are also many so-called art genres in the square design, so aesthetics is also a very important element in the square design.

\section{B. The role of cultural elements in the square}

Although the concept and design method of modern square design is introduced by Western Square design, it has unique advantages in expressing Chinese traditional culture. First of all, the plaza carries the life functions of many urban people. With its traffic and recreation, it becomes an important activity place for people to enjoy leisure, entertainment, communication and gathering, and it is unique in the whole urban space composition. Importance becomes part of urban planning and design. The important function of the modern square in the entire modern city determines that the square also conveys more cultural connotations for the city. Secondly, the space of the square is more favorable to the display of the culture of the square. The square is generally larger in size, and the sculptures above the square are more likely to form a spatial sequence with a strong visual sense. For example, the large-scale sculpture design of the Big Wild Goose Pagoda Square reproduces the life of the Tang Dynasty and the status of historical figures. This shows that the square plays a role in bearing cultural connotations.

\section{APPLICATION OF DECORATIVE ART OF TRADITIONAL RESIDENTIAL HOUSES IN GUANZHONG, SHAANXI PROVINCE IN SQUARE DESIGN}

\section{A. Application in the design of square buildings}

With the transformation of modern urban design, modern square design is no longer only religious, gathering and other simple human activities, and its content is rich and colorful. As an important part of the square, architecture has also been given more and more functions.

The buildings in the modern square are divided into different functions according to different functions: entertainment, tourism, and service. Therefore, architects are required to highlight local characteristics while designing.

Modern buildings are simple and bright, and new materials such as glass and steel are used. The architectural color of warm and cold, light and dark has caused people's imagination. Its symbolism and texture make the buildings in the Guanzhong area characterized by simplicity and vitality.

\section{B. Application in the design of square structures}

The square structures have their own specific missions. The sculptures are perhaps about the most representative figures and events that took place in a historical period. They convey the fact that people can't forget history and inspire people to cherish the good life of the present.

The most common in the square structure is the landscape wall, which is flexible in form and diverse in structure. It can be a lonely wall, or it can be part of the most representative building of a period, or it can be a way of using Chinese gardening to frame the scene and block the line of sight. The choice of materials can be either traditional brick or reinforced concrete or reinforced concrete. In the specific design, for the performance of the wall, we can usually use the common patterns of doors and windows in the Guanzhong area and at the same time refine it into cultural symbols, using hollow carving and other design techniques to make the wall more local cultural characteristics.

\section{Application in the design of square pavement}

Paving is one of the important elements in landscape design. The function and theme type of urban public space determine the material and form of pavement. As one of the types of urban public space, the square plays the role of organizing urban traffic and is connected with the main roads of the city to meet the functions of crowd activities and crowd distribution.

Guanzhong Architecture has the characteristics of Chinese classical architecture and the unique charm of Sanqin Earth. Guanzhong's architectural decoration patterns show the locality and long history of Guanzhong. At present, there is no systematic discussion on the protection of traditional architectural culture. Taking Guanzhong architecture as an example, Guanzhong architecture is gradually disappearing. There are many reasons for this phenomenon, including the development of urban economy and population growth, and new things to replace old things. It is the development trend of things. Therefore, the carrier of traditional culture should be applied to 
the important elements of square design, and it is a good embodiment of humanism.

\section{REFERENCES}

[1] Kubota T, Zakaria M A, Abe S, et al, Thermal functions of internal courtyards in traditional Chinese shophouses in the hot-humid climate of Malaysia, Building \& Environment, vol.112, pp. 115-131, 2017.

[2] Tafti F A, Rezaeian M, Razavi S Z E, Sunken courtyards as educational environments: Occupant's perception and environmental satisfaction, Tunnelling \& Underground Space Technology, vol.78, pp. 124-134, 2018.

\section{SUMMARY}

More and more ideas and design techniques in modern squares are cited. It is no longer a simple activity space, but a complex space design combined with architecture and planning. This provides a space for the feasibility of building decorative arts. The decorative components of the Guanzhong building conform to the rhythm of the overall building, giving full play to the advantages of the components in terms of materials and colors. The building and decorative components complement each other so that people can feel the simplicity and heavy feeling of Guanzhong architecture. The square structure can be used as a continuation of the building, which can increase the landscape experience of the square. The application of architectural art deco also has a lot of space in the structure, and it is also a key research area. Decoration has always been one of
[3] Rand H.M. Agha, John M. Kamara, Adaptations in traditional courtyard houses in Baghdad, Iraq, International Journal of Building Pathology and Adaptation, vol.35, pp. 348-363, 2017.

[4] Yu S, Courtyard in conflict: the transformation of Beijing's Siheyuan during revolution and gentrification, Journal of Architecture, vol.22, pp. 1-29, 2017.

[5] Bougdah H, The Courtyard House: Can a Sustainable Future Learn from a Context Relevant Past, Social Science Electronic Publishing, vol.1, pp. 9, 2017.

[6] Soflaei F, Shokouhian M, Abraveshdar H, et al, The impact of courtyard design variants on shading performance in hot- arid climates of Iran, Energy \& Buildings, vol.143, pp. 71-83, 2017.

[7] Song Y, Li J, Wang J, et al, Multi-criteria approach to passive space design in buildings: Impact of courtyard spaces on public buildings in cold climates, Building \& Environment, vol.89, pp. 295-307, 2015.

[8] Jin L, Zhao L, Meng Q, et al, Optimization analysis on the indoor thermal environment of rural residential buildings in Guangdong Province, Journal of Civil Architectural \& Environmental Engineering, vol.37, pp. 116-126, 2015. 